\title{
Predictors of spontaneous bacterial peritonitis in Romanian adults with liver cirrhosis: Focus on the neutrophil-to-lymphocyte ratio
}

\author{
ROXANA-EMANUELA POPOIAG ${ }^{1}$, ANDRA-IULIA SUCEVEANU ${ }^{2}$, ADRIAN-PAUL SUCEVEANU ${ }^{2 *}$, \\ SERGIU IOAN MICU ${ }^{2}$, FELIX VOINEA ${ }^{3}$, LAURA MAZILU ${ }^{4}$, LUCIAN CRISTIAN PETCU ${ }^{5 *}$, \\ EUGENIA PANAITESCU ${ }^{6}$, GEORGETA COZARU ${ }^{7}$ and CARMEN FIERBINȚEANU-BRATICEVICI ${ }^{8}$
}

\author{
${ }^{1}$ Department of Internal Medicine, Faculty of Medicine, 'Ovidius' University, 900527 Constanta; \\ Departments of ${ }^{2}$ Gastroenterology, ${ }^{3}$ Urology and ${ }^{4}$ Oncology, Emergency Clinical Hospital 'St. Apostle Andrew', \\ 900591 Constanta; ${ }^{5}$ Department of Biophysics and Biostatistics, Dentistry Faculty, 'Ovidius' University, \\ 900527 Constanta; ${ }^{6}$ Department of Informatics and Biostatistics, 'Carol Davila' University of Medicine and Pharmacy, \\ 050474 Bucharest; ${ }^{7}$ Pathology Department, Emergency Clinical Hospital ‘St. Apostle Andrew', \\ 900591 Constanta; ${ }^{8}$ Department of Gastroenterology, University Emergency Hospital, 050098 Bucharest, Romania
}

Received May 10, 2021; Accepted June 9, 2021

DOI: $10.3892 / \mathrm{etm} .2021 .10415$

\begin{abstract}
Spontaneous bacterial peritonitis (SBP) is a severe complication of liver cirrhosis whose diagnosis is based on a polymorphonuclear leukocyte (PMN) value $>250 \mathrm{~mm}^{3}$, yet this PMN value cannot identify all existing types. The aim of our study was to determine the clinical and biological factors that were associated with SBP and predict its occurrence, focusing on the neutrophil-to-lymphocyte ratio (NLR) as one of them. Our retrospective study included 216 patients with liver cirrhosis who were hospitalized between December 2019 and January 2010 at the Emergency County Clinical Hospital of 'St. Apostle Andrew' in Constanta, Romania. Demographic, clinical, and laboratory data were collected from patient observation sheets. The patients were divided into two groups: One group of patients with SBP and the other without SBP. The diagnosis of SBP was made when patients presented with PMN $>250 \mathrm{~mm}^{3}$ and other causes of secondary bacterial peritonitis were excluded. The mean age of the patients was $61.25 \pm 10.67$ years, and the alcoholic etiology of liver cirrhosis was most common (44\%). Univariate logistic regression analysis showed that there was an association between biological parameters, such as serum white blood cells, total platelet count, total bilirubin, serum albumin, international normalized ratio, creatinine, erythrocyte sedimentation rate (ESR), serum sodium, alkaline reserve, and NLR, and clinical
\end{abstract}

Correspondence to: Professor Andra-Iulia Suceveanu, Department of Gastroenterology, Emergency Clinical Hospital 'St. Apostle Andrew', 145 Tomis Boulevard, 900591 Constanta, Romania

E-mail: andrasuceveanu@yahoo.com

*Contributed equally

Key words: liver cirrhosis, ascites, spontaneous bacterial peritonitis, predictors, neutrophil-to-lymphocyte ratio parameters, such us upper gastrointestinal bleeding and cardiac comorbidities in the occurrence of SBP. Multivariate analysis identified ESR and NLR as predictive factors in the occurrence of SBP. The area under the curve (AUC) was $0.916[\mathrm{P}<0.001$, 95\% confidence interval (CI) 0.870-0.949] for ESR and AUC was $0.963(\mathrm{P}<0.001,95 \%$ CI $0.928-0.984)$ for NLR, respectively. In conclusion, the combination of these 2 biological parameters is useful in identifying or excluding SBP.

\section{Introduction}

According to the Hepa Health project, a study conducted in 35 European and 5 Asian countries which is considered by the European Association for the Study of the Liver (EASL), the prevalence of liver cirrhosis and other chronic liver disease increases to some extent from Western European countries to Eastern European countries. However, the highest prevalence is found in Central European countries, including Romania and Austria with over 1,100 cases per 100,000 individuals. In addition, the highest mortality rates for liver disease were identified in Romania (36 deaths per 100,000), Lithuania and Hungary (approximately 20 deaths per 100,000) (1).

According to a systematic study conducted between 2005 and 2015 by the European Center for Disease Prevention and Control (ECDC), countries in Southern and Eastern Europe had a higher prevalence of hepatitis B virus (HBV) and hepatitis $\mathrm{C}$ virus (HCV) than northern and western countries. The prevalence of HBV ranged from $0.1 \%$ in Ireland to $4.4 \%$ in Romania. Greece and Romania have the highest prevalence of 3.3 and $4.4 \%$, respectively, while the other countries have a prevalence of approximately $1 \%$. The same countries registered the highest prevalence of HCV (2.2 and 3.2\%) (2).

Spontaneous bacterial peritonitis (SBP) is one of the most common complications of patients with cirrhosis and ascites, with an incidence between $10-30 \%$ and an estimated in-hospital mortality rate of $20 \%$ (3). According to the European guideline, the diagnosis is based on a polymorphonuclear leukocyte (PMN) value in ascites fluid $>250 \mathrm{~mm}^{3}$ in 
the absence of secondary causes of intra-abdominal infection. There is a variant in which the PMN value is $<250 \mathrm{~mm}^{3}$, but with present culture called monomicrobial bacterascitis (4). Despite the diagnostic and treatment recommendations in the guideline, in a retrospective study made in the USA, only $52.4 \%$ of patients diagnosed with SBP met the criteria and only $67.3 \%$ of patients received appropriate treatment (5). The diagnostic challenge lies in the fact that the symptomatology of patients with SBP varies from typical symptoms to their partial or complete absence. Therefore, a prompt diagnosis and effective treatment can reduce the poor outcome rate (6).

Recent research has focused on identifying non-invasive parameters useful in SBP prediction. Multiple laboratory tests and clinical factors have been identified as predictive factors: international normalized ratio (INR) (7), creatinine, total bilirubin (BT), serum white blood cells (WBC), prothrombin time (8) C-reactive protein (CRP), total platelet count (PLT) (9) severe ascites (7), Child Pugh score (10) and Model for End-Stage Liver Disease (MELD) score $(10,11)$.

The aim of our study was to identify other predictive factors in the occurrence of SBP in adult Romanian population, given that the available data are numerous but contradictory. There is a high need for an early diagnosis considering the high mortality rate mentioned above.

\section{Patients and methods}

Patients. This study has a retrospective, observational, and non-interventional design and was approved by the Emergency Clinical Hospital 'St. Apostle Andrew' Constanta Ethics Committee. Although not mandatory for observational, non-interventional studies at the Emergency Clinical Hospital 'St. Apostle Andrew' from Constanta, a university hospital, all admitted patients signed informed consent by which they agreed that their data be available for academic and scientific purposes.

The study included 216 patients with liver cirrhosis of various etiologies (with a mean age of $61.2 \pm 10.67$ years, $65.7 \%$ males and $34.3 \%$ females), hospitalized at the County Emergency Clinical Hospital, Constanța, between December 2019 and January 2010. Patients $>18$ years were divided into two groups: 72 patients with SBP and 144 patients without SBP. The diagnosis of SBP was performed according to the European guideline, namely a PMN value $>250 \mathrm{~mm}^{3}$ with or without a positive culture. Patients with intra-abdominal surgical causes of peritonitis or other infectious causes (respiratory, urinary) were excluded. Data from the first day of admission regarding age, sex, etiology of cirrhosis, laboratory blood tests and ascites fluid tests, Child Pugh score, complications and comorbidities, were recorded from the medical files. The neutrophil-to-lymphocyte ratio was calculated by dividing the neutrophil count by the lymphocyte count.

Statistical analysis. The software used was SPSS version 23 (IBM Corp.). Numerical data were synthesized as mean and standard deviation and qualitative data were recorded as percentages. Differences between the two groups were tested using the independent samples t-test, Mann-Whitney U test, and Pearson's Chi-square test. Univariate logistic regression analysis was used to compare the two groups. Multivariate logistic regression analysis was performed to identify predictive factors for SBP occurrence. In order to test the diagnostic accuracy of the evaluated markers for SBP diagnosis, we used the area under the curve (AUC). The optimum cut-off value was identified using Youden index. For the optimal cut-off value, the sensitivity, and specificity were calculated. P-values of $<0.05$ were considered statistically significant.

\section{Results}

Patient characteristics. Patient characteristics are described by comparison between the group of patients with SBP and those without SBP. Of the 216 patients with cirrhosis, 72 patients $(33.3 \%)$ had SBP and 144 patients did not have SBP (66.67\%). In the group of patients who had SBP, $33.3 \%$ were women and $66.7 \%$ were men, with a mean age of $59.29 \pm 11.30$ years. Among the patients without SBP $34.7 \%$ were women and $65.3 \%$ were men, with a mean age of $62.23 \pm 10.25$ years.

The most common etiologies of liver cirrhosis in the group of patients with SBP were represented by: Alcoholic (52.8\%), HCV (16.7\%), mixed (13.9\%), HBV (12.5\%) and others (4.1\%). Regarding the mixed etiology, 6 cases had HCV+alcohol, 4 cases had $\mathrm{HBV}+\mathrm{HCV}$ and 3 cases with autoimmune etiology were classified as others. In the group of patients without SBP, the causes of liver cirrhosis were represented by: Alcoholic (39.6\%), mixed (27.1\%), HCV (19.4\%), HBV (11.8\%) and others $(2.1 \%)$. For mixed etiology, there were 10 cases with $\mathrm{HBV}+$ alcohol, 16 cases with $\mathrm{HCV}+$ alcohol, 5 cases with $\mathrm{HBV}+\mathrm{HCV}, 8$ cases with $\mathrm{HBV}+\mathrm{HDV}$ and 3 cases were classified as others ( 2 cases with autoimmune etiology and 1 case of cryptogenic etiology). The data are shown in Table I.

There was a significant difference in Child Pugh class B and $\mathrm{C}$ scores in patients with SBP and those without SBP (26.4 vs. $70.1 \%, 70.8$ vs. $28.5 \%, \mathrm{P}<0.001)$. In contrast, there were no significant differences in age, sex or etiology of liver cirrhosis $(\mathrm{P}=0.061, \mathrm{P}=0.839$ and $\mathrm{P}=0.217$, respectively) between the two groups.

Patients in the SBP group had significantly higher serum WBC, BT, INR, creatinine, erythrocyte sedimentation rate (ESR), neutrophil-to-lymphocyte ratio (NLR), and PMN than patients in the non-SBP group (all with $\mathrm{P}<0.001$ ). In addition, the mean values of PLT, serum albumin, sodium $(\mathrm{Na})$, and alkaline reserve (AR) were significantly lower in patients with SBP than those without SBP $(\mathrm{P}<0.001$ for the first 4 variables, $\mathrm{P}=0.001$ for the last one). There were no significant differences in the mean values of hemoglobin $(\mathrm{Hb})$, aspartate aminotransferase (AST), and alanine aminotransferase (ALT), $(\mathrm{P}=0.222$, $\mathrm{P}=0.815$ and $\mathrm{P}=0.198$, respectively).

Regarding the complications, there were significant differences between the group with SBP and the group without SBP regarding upper gastrointestinal bleeding (UGIB) (66.7 vs. $22.9 \%, \mathrm{P}<0.001)$ but not in the case of hepatic encephalopathy (HE), (34.7 vs. $31.3 \%, \mathrm{P}=0.607)$. Patients without SBP had a higher proportion of cardiac comorbidities than patients with SBP (42.4 vs. $25 \%, \mathrm{P}=0.016$ ). There were no significant differences between the two groups regarding pulmonary $(\mathrm{P}=0.326)$, renal $(\mathrm{P}=0.661)$, digestive $(\mathrm{P}=0.682)$ or metabolic $(\mathrm{P}=0.298)$ comorbidities (Table II).

Univariate logistic regression for predictive factors in SBP occurrence. Using univariate analysis, 12 variables were identified as 
Table I. Characteristics of the patients with and without SBP by comparison.

\begin{tabular}{|c|c|c|c|c|}
\hline Category & $\begin{array}{c}\text { Total } \\
(n=216)\end{array}$ & $\begin{array}{l}\text { With SBP } \\
(\mathrm{n}=72)\end{array}$ & $\begin{array}{l}\text { Without SBP } \\
\qquad(\mathrm{n}=144)\end{array}$ & P-value \\
\hline Age, years $($ mean \pm SD) & $61.25 \pm 10.67$ & $59.29 \pm 11.30$ & $62.23 \pm 10.25$ & 0.061 \\
\hline \multicolumn{5}{|l|}{ Sex, n/total (\%) } \\
\hline Female & $74 / 216(34.3)$ & $24 / 72(33.3)$ & $50 / 144(34.7)$ & 0.839 \\
\hline Male & $142 / 216(65.7)$ & $48 / 72(66.7)$ & $94 / 144(65.3)$ & \\
\hline \multicolumn{5}{|l|}{ Etiology, n/total (\%) } \\
\hline Alcoholic & $95 / 216(44.0)$ & $38 / 72(52.8)$ & $57 / 144(39.6)$ & \\
\hline Viral B & 26/216 (12.0) & $9 / 72(12.5)$ & 17/144 (11.8) & 0.217 \\
\hline Viral C & 40/216 (18.5) & $12 / 72(16.7)$ & 28/144 (19.4) & \\
\hline $\begin{array}{l}\text { Mixed (alcoholic+viral B/C, } \\
\text { viral } B+C \text {, viral } B+D)\end{array}$ & $49 / 216(22.7)$ & $10 / 72(13.9)$ & $39 / 144(27.1)$ & \\
\hline Others & $6 / 216(2.8)$ & $3 / 72(4.1)$ & $3 / 144(2.1)$ & \\
\hline \multicolumn{5}{|l|}{ Child Pugh, n/total (\%) } \\
\hline Grade A & 4/216 (1.9) & $2 / 72(2.8)$ & 2/144 (1.4) & \\
\hline Grade B & $120 / 216(55.6)$ & $19 / 72(26.4)$ & $101 / 144(70.1)$ & $<0.001$ \\
\hline Grade C & $92 / 216(42.6)$ & $51 / 72(70.8)$ & $41 / 144(28.5)$ & \\
\hline Serum WBC $\left(10^{3} / \mu 1\right)$ & $8.44 \pm 4.40$ & $12.61 \pm 4.24$ & $6.36 \pm 2.53$ & $<0.001$ \\
\hline $\operatorname{PLT}\left(10^{3} / \mu 1\right)$ & 137.22354 .9 & $115.32 \pm 32.56$ & $147.07 \pm 57.46$ & $<0.001$ \\
\hline $\mathrm{Hb}(\mathrm{mg} / \mathrm{dl})$ & $10.91 \pm 1.54$ & $11.09 \pm 1.70$ & $10.82 \pm 1.45$ & 0.222 \\
\hline BT (mg/dl) & $3.1 \pm 1.97$ & $4.45 \pm 2.30$ & $2.44 \pm 1.36$ & $<0.001$ \\
\hline Serum albumin (g/dl) & $2.62 \pm 0.51$ & $2.49 \pm 0.44$ & $2.68 \pm 0.54$ & $<0.001$ \\
\hline INR & $1.82 \pm 0.62$ & $2.24 \pm 0.83$ & $1.61 \pm 0.34$ & $<0.001$ \\
\hline $\begin{array}{l}\text { Creatinine } \\
(\mathrm{mg} / \mathrm{dl})\end{array}$ & $1.31 \pm 0.96$ & $1.53 \pm 1.19$ & $1.17 \pm 0.69$ & $<0.001$ \\
\hline AST (U/l) & $77.46 \pm 37.96$ & $78.32 \pm 36.68$ & $77.03 \pm 38.71$ & 0.815 \\
\hline ALT (U/l) & $46.15 \pm 23.0$ & $49.01 \pm 23.42$ & $44.72 \pm 22.82$ & 0.198 \\
\hline $\operatorname{ESR}(\mathrm{mm} / \mathrm{h})$ & $30.61 \pm 12.04$ & $42.11 \pm 12.09$ & $24.85 \pm 6.76$ & $<0.001$ \\
\hline NLR & $2.48 \pm 1.18$ & $3.67 \pm 1.13$ & $1.87 \pm 0.49$ & \\
\hline $\begin{array}{l}\text { Ascites WBC } \\
\left(\text { cells } / \mathrm{mm}^{3}\right)\end{array}$ & $615.94 \pm 933.648$ & $1611 \pm 1060.17$ & $117.98 \pm 58.73$ & $<0.001$ \\
\hline $\mathrm{PMN}\left(\right.$ cells $/ \mathrm{mm}^{3}$ ) & $442.02 \pm 826.535$ & $1,266.05 \pm 1016.55$ & $25.40 \pm 23.97$ & $<0.001$ \\
\hline $\mathrm{Na}(\mathrm{mmol} / \mathrm{l})$ & $132 \pm 7.59$ & $128.06 \pm 9.96$ & $133.97 \pm 5.07$ & $<0.001$ \\
\hline $\mathrm{AR}(\mathrm{mmol} / \mathrm{l})$ & $21.3 \pm 4.43$ & $19.85 \pm 6.02$ & $22.02 \pm 3.15$ & 0.001 \\
\hline
\end{tabular}

SBP, spontaneous bacterial peritonitis; WBC, white blood cells; PLT, platelet count; Hb, hemoglobin; BT, total bilirubin; INR, international normalized ratio; AST, aspartate aminotransferase; ALT, alanine aminotransferase; ESR, erythrocyte sedimentation rate; NLR, neutrophil-to-lymphocyte ratio; PMN, polymorphonuclear leukocyte; Na, sodium; AR, alkaline reserve. Data are presented as mean \pm SD or frequency (\%). Significant P-values are shown in bold print.

predictive factors in the occurrence of SBP: Serum WBC (OR, 1.61), PLT (OR, 0.98), BT (OR, 1.79), serum albumin (OR, 0.46), INR (OR, 6.82), creatinine (OR, 1.52), ESR (OR, 1.30), serum Na (OR, 0.89), AR (OR, 0.89), NLR (OR, 138.2), UGIB (OR, 6.72), and cardiac comorbidities (OR, 0.45) (Table III).

Multivariate analysis. ESR (OR, 1.30) and NLR (OR, 371.36) were identified as independent predictive factors in the occurrence of SBP. The logistic regression model obtained from ESR and NLR explains $64.04 \%$ (Cox \& Snell R ${ }^{2}$ ) to $88.95 \%$ $\left(\right.$ Nagelkerke $\mathrm{R}^{2}$ ). In addition, the program reports $\mathrm{AUC}=0.990$; 95\% CI, 0.965-0.999 constructed for the combination of independent variables (Fig. 1 and Table IV).
Using receiver operating characteristic (ROC) statistics, the sensitivity and specificity of ESR, at a cut-off value of $>33 \mathrm{~mm} / \mathrm{h}$, for the diagnosis of SBP, were 80.56 and $87.50 \%$, respectively. The sensitivity and specificity of NLR, at a cut-off value of $>2.4$, were 98.61 and $81.94 \%$, respectively (Fig. 2 and Table V).

\section{Discussion}

Patients with liver cirrhosis are prone to infections, SBP being among the most common, with a variable prevalence but with a high mortality rate (6). For this reason, it is necessary to identify non-invasive, inexpensive, easy-to-achieve factors that are associated with SBP and have a predictive role. 
Table II. Characteristics of the patients with and without SBP regarding complications and comorbidities.

\begin{tabular}{llll}
\hline Category & \multicolumn{1}{l}{$\begin{array}{c}\text { With SBP } \\
(\mathrm{n}=72)\end{array}$} & $\begin{array}{c}\text { Without SBP } \\
(\mathrm{n}=144)\end{array}$ & \\
\hline Complications, n/total (\%) & & & \\
UGIB & $48 / 72(66.7 \%)$ & $33 / 144(22.9 \%)$ & \\
HE & $25 / 72(34.7 \%)$ & $45 / 144(31.3 \%)$ & 0.607 \\
Comorbidities, n/total (\%) & & $30 / 144(20.8 \%)$ & 0.326 \\
Pulmonary & $11 / 72(15.3 \%)$ & $36 / 144(25 \%)$ & 0.661 \\
Renal & $20 / 52(27.8 \%)$ & $46 / 144(31.9 \%)$ & 0.682 \\
Digestive & $25 / 72(34.7 \%)$ & $35 / 144(24.3 \%)$ & 0.298 \\
Metabolic & $13 / 72(18.1 \%)$ & $61 / 144(42.4 \%)$ & $\mathbf{0 . 0 1 6}$ \\
Cardiac & $18 / 72(25 \%)$ & & \\
\hline
\end{tabular}

SBP, spontaneous bacterial peritonitis; UGIB, upper gastrointestinal bleeding; HE, hepatic encephalopathy. Data are presented as frequencies (\%). Significant P-values are shown in bold print.

Table III. Univariate logistic regression analysis of predictive factors for SBP occurrence.

\begin{tabular}{lccc}
\hline Parameters & P-value & OR value & 95\% CI \\
\hline Serum WBC $\left(10^{3} / \mu \mathrm{l}\right)$ & $<0.001$ & 1.61 & $1.42-1.83$ \\
PLT $\left(10^{3} / \mu \mathrm{l}\right)$ & $<0.001$ & 0.98 & $0.98-0.99$ \\
BT $(\mathrm{mg} / \mathrm{dl})$ & $<0.001$ & 1.79 & $1.49-2.16$ \\
Serum albumin $(\mathrm{g} / \mathrm{dl})$ & $<0.001$ & 0.46 & $0.25-0.82$ \\
INR & $<0.001$ & 6.82 & $3.50-13.29$ \\
Creatinine $(\mathrm{mg} / \mathrm{dl})$ & $<0.001$ & 1.52 & $1.13-2.05$ \\
ESR $(\mathrm{mm} / \mathrm{h})$ & $<0.001$ & 1.30 & $1.20-1.40$ \\
Na $(\mathrm{mmol} / \mathrm{l})$ & $<0.001$ & 0.89 & $0.85-0.93$ \\
AR $(\mathrm{mmol} / \mathrm{l})$ & 0.001 & 0.89 & $0.83-0.95$ \\
NLR & $<0.001$ & 138.2 & $26.4-724.2$ \\
UGIB & $<0.001$ & 6.72 & $3.59-12.57$ \\
Cardiac comorbidities & 0.013 & 0.45 & $0.24-0.85$ \\
\hline
\end{tabular}

SBP, spontaneous bacterial peritonitis; OR, odds ratio; 95\% CI, 95\% confidence interval; WBC, white blood cell count; PLT, platelet count; BT, total bilirubin; INR, international normalized ratio; ESR, erythrocyte sedimentation rate; Na, sodium; AR, alkaline reserve; NLR, neutrophil-to-lymphocyte ratio; UGIB, upper gastrointestinal bleeding.

Table IV. Multivariate analysis by logistic regression for SBP prediction.

\begin{tabular}{lrcr}
\hline Variable & OR & $95 \%$ CI & P-value \\
\hline ESR & 1.3023 & $1.1448-1.4815$ & 0.001 \\
NLR & 371.3660 & $26.1400-5275.9269$ & $<0.001$ \\
\hline
\end{tabular}

SBP, spontaneous bacterial peritonitis; OR, odds ratio; CI, confidence interval; ESR, erythrocyte sedimentation rate; NLR, neutrophil-tolymphocyte ratio.

The etiology of liver cirrhosis varies geographically. The most common etiology in our study was found to be alcohol, similar to that in a study by Gonçalves et al (12) in Brazil.
However, our findings differed in studies from Africa, $(7,13)$ where leading etiology was HBV.

Our study showed that there was a significant difference between the mean values of BT, creatinine, INR, serum WBC, serum albumin and PLT in the SBP group compared to those without SBP. The mean values of BT, creatinine, INR, and serum WBC were significantly higher, and the mean PLT was significantly lower, in a group of 59 patients with SBP from a study with 300 patients with liver cirrhosis (14). But in contrast with our study results, there was no statistically significant difference in serum albumin values between the groups. Following the univariate analysis, in their study, 9 variables were identified as predictive factors in the occurrence of SBP, namely: age, BT, aspartate aminotransferase (AST), creatinine, INR, serum leukocytes, platelets, Model for End-Stage Liver Disease (MELD) score and C-reactive protein (CRP) (14). Our univariate analysis did not record age 
Table V. Diagnostic accuracy of ESR and NLR to predict occurrence of SBP.

\begin{tabular}{|c|c|c|c|c|c|c|}
\hline Variable & AUC & P-value & $95 \% \mathrm{CI}$ & Cut-off & Sensitivity & Specificity \\
\hline ESR & 0.916 & $<0.001$ & $0.870-0.949$ & $>33$ & 80.56 & 87.50 \\
\hline NLR & 0.963 & $<0.001$ & $0.928-0.984$ & $>2.4$ & 98.61 & 81.94 \\
\hline
\end{tabular}

SBP, spontaneous bacterial peritonitis; AUC, area under the curve; CI, confidence interval; ESR, erythrocyte sedimentation rate; NLR, neutrophil-to-lymphocyte ratio.

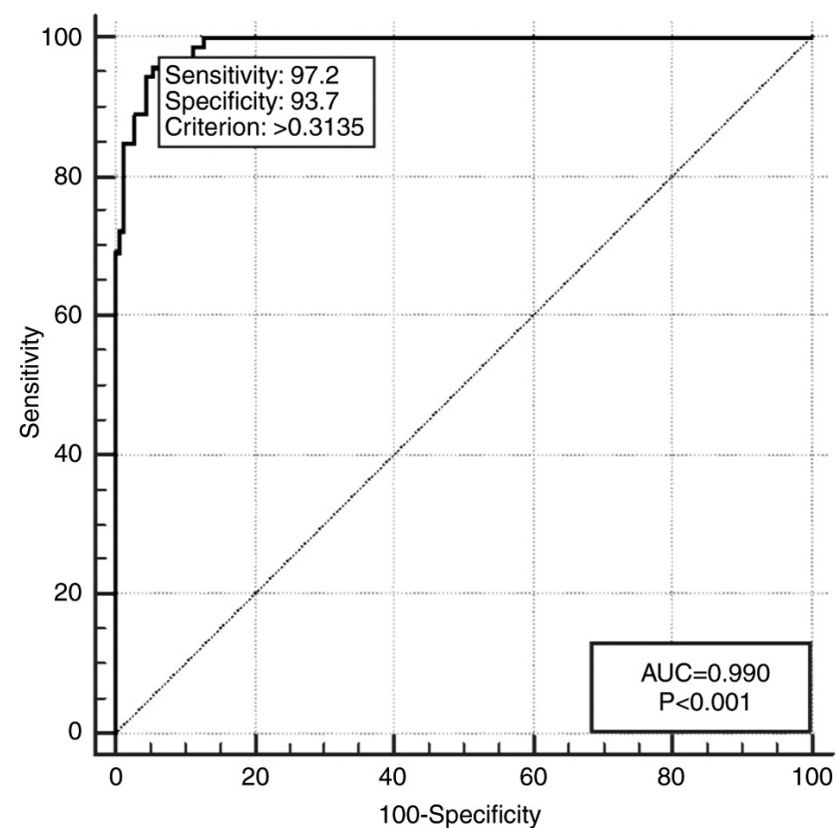

Figure 1. Diagnostic accuracy of the model consisting of ESR and NLR for the occurrence of SBP. SBP, spontaneous bacterial peritonitis; AUC, area under the curve; ESR, erythrocyte sedimentation rate; NLR, neutrophil-to-lymphocyte ratio.

and AST as predictive factors for SBP but identified albumin as one of them, and data concerning the MELD score and CRP were not registered.

The results of our study showed that there were significant differences in the mean value of PMN and ascites proteins between the SBP and non-SBP groups but no significant differences between the mean value of $\mathrm{Hb}, \mathrm{AST}$, and alanine aminotransferase (ALT) were registered. Similar to our study results, Abdel Rahman et al (15) in a study of 80 patients with liver cirrhosis divided into two equal groups, with and without $\mathrm{SBP}$, the mean values of $\mathrm{Hb}$, AST and ALT did not differ significantly between the two groups but the median values of PMN differed significantly. Contrary to our study, creatinine values were similar in both groups.

Although the univariate analysis in our study identified multiple factors involved in the occurrence of SBP including serum biological parameters (WBC, PLT, creatinine, BT, serum albumin, Na, alkaline reserve, INR, ESR and NLR), ascites fluid analysis (WBC and PMN) and clinical parameters [upper gastrointestinal bleeding (UGIB), cardiac comorbidities] only 2 factors (ESR and NLR) were identified as independent predictive factors with good accuracy for SBP diagnosis. In contrast, in the

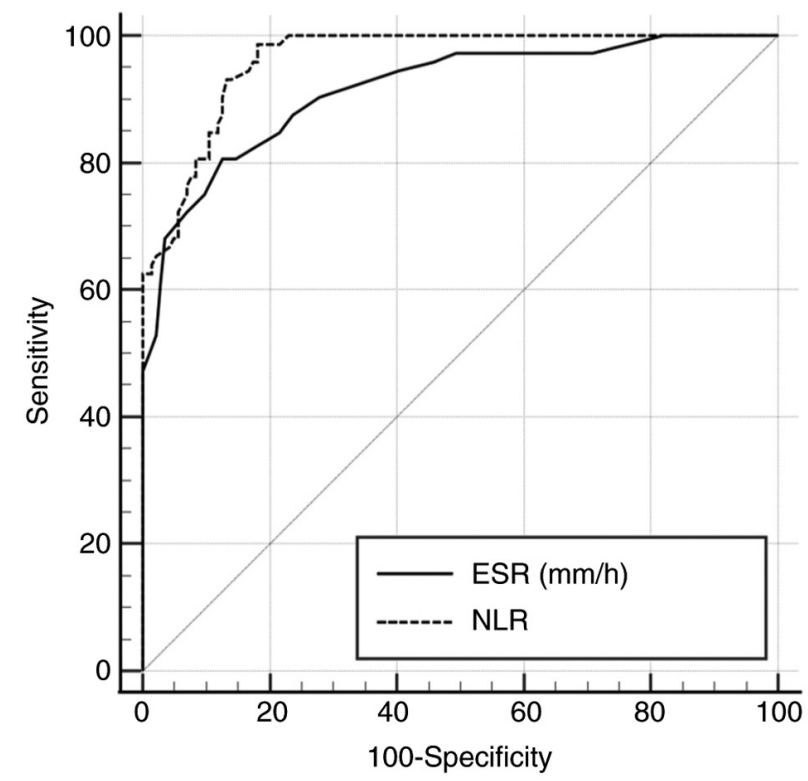

Figure 2. Sensitivities and specificities of ESR and NLR for SBP occurrence. SBP, spontaneous bacterial peritonitis; ESR, erythrocyte sedimentation rate; NLR, neutrophil-to-lymphocyte ratio.

study by Elsadek et al (16) that included 178 patients with liver cirrhosis, of which 60 with SBP and 118 without SBP, the diagnostic accuracy of ESR $(\mathrm{AUC}=0.679 ; 95 \% \mathrm{CI}$, $0.581-0.776)$ and the cut-off value $(27.0 \mathrm{~mm} / \mathrm{h})$ were lower compared to our study.

NLR is a non-invasive marker that can be used to predict the occurrence of in-hospital infections in patients with decompensated liver cirrhosis (17). In a study conducted by Piotrowski et al, an association between NLR and the presence of infection in patients with liver cirrhosis was identified but with low diagnostic accuracy (AUC=0.606) (18).

Our study showed that a model consisting of NLR and ESR has a high accuracy in SBP diagnosis. Moreover, according to literature data, NLR can be used in combination with other factors as a predictor in the occurrence of SBP. Abdel-Razik et al (19) demonstrated that a combination of age, mean platelet volume (MPV), NLR and CRP, used as the Mansoura score, can rule out the diagnosis of SBP. Mousa et al (20) showed that a combination of NLR and CRP can be used as a simple and non-invasive test for SBP diagnosis. However, data are contradictory in terms of the cut-off value.

Our study had several limitations. Namely, it was a single center retrospective study and did not record data on CRP, as it was absent from most of the patient medical files. 
In conclusion, the present study could be of clinical utility in predicting SBP, a major cause of mortality in patients with cirrhosis. The combination of NLR and ESR is an easy test that can be used to diagnose SBP.

\section{Acknowledgements}

Not applicable.

\section{Funding}

No funding was received.

\section{Availability of data and materials}

All data generated or analyzed during this study are included in this published article.

\section{Authors' contributions}

REP, CFB, AIS and APS conceived and designed the study. REP, SIM and FV acquired the data; EP, LM, FV, GC and LCP analyzed the data; CFB, AIS, APS and LCP validated the results. EP, FV, LM, and SIM were responsible for preparation of the original draft; REP, CFB, SIM, GC and APS were responsible for the final manuscript editing. REP, AIS, LM, GC and LCP supervised the manuscript publication. All authors read and approved the final manuscript for publication.

\section{Ethics approval and consent to participate}

The present study was approved by the Emergency Clinical Hospital 'St. Apostle Andrew' Constanta Ethics Committee. Although not mandatory for observational, non-interventional studies at the Emergency Clinical Hospital 'St. Apostle Andrew' from Constanta, a university hospital, all admitted patients signed informed consent by which they agreed that their data be available for academic and scientific purposes.

\section{Patient consent for publication}

Not applicable.

\section{Competing interests}

The authors declare that they have no competing interests.

\section{References}

1. Pimpin L, Cortez-Pinto H, Negro F, Corbould E, Lazarus JV, Webber L and Sheron N; EASL HEPAHEALTH Steering Committeey: Burden of liver disease in Europe: Epidemiology and analysis of risk factors to identify prevention policies. J Hepatol 69: 718-735, 2018.

2. European Centre for Disease Prevention and Control (ECDC): Systematic review on hepatitis B and $C$ prevalence in the EU/EEA ECDC, Stockholm, 2016. https://www.ecdc.europa.eu/en/publications-data/systematic-review-hepatitis-b-and-c-prevalence-eueea. Accessed November 10, 2016.
3. Dever JB and Sheikh MY: Review article: Spontaneous bacterial peritonitis-bacteriology, diagnosis, treatment, risk factors and prevention. Aliment Pharmacol Ther 41: 1116-1131, 2015.

4. European Association for the Study of the Liver: EASL clinical practice guidelines on the management of ascites, spontaneous bacterial peritonitis, and hepatorenal syndrome in cirrhosis. J Hepatol 53: 397-417, 2010.

5. Numan L, Elkafrawy A, Kaddourah O, Brotherton T, Saeed L, Zafar Y, Tomaw A, Foxworth J and Al-Sayyed L: Spontaneous bacterial peritonitis: We are still behind. Cureus 12: e7711, 2020.

6. Marciano S, Díaz JM, Dirchwolf M and Gadano A: Spontaneous bacterial peritonitis in patients with cirrhosis: Incidence, outcomes, and treatment strategies. Hepat Med 11: 13-22, 2019.

7. Duah A and Nkrumah KN: Prevalence and predictors for spontaneous bacterial peritonitis in cirrhotic patients with ascites admitted at medical block in Korle-Bu Teaching Hospital, Ghana. Pan Afr Med J 33: 35, 2019.

8. Shi KQ, Fan YC, Ying L, Lin XF, Song M, Li LF, Yu XY, Chen YP and Zheng MH: Risk stratification of spontaneous bacterial peritonitis in cirrhosis with ascites based on classification and regression tree analysis. Mol Biol Rep 39: 6161-6169, 2012.

9. Wehmeyer MH, Krohm S, Kastein F, Lohse AW and Lüth S: Prediction of spontaneous bacterial peritonitis in cirrhotic ascites by a simple scoring system. Scand J Gastroenterol 49: 595-603, 2014.

10. Paul K, Kaur J and Kazal HL: To study the incidence, predictive factors and clinical outcome of spontaneous bacterial peritonitis in patients of cirrhosis with ascites. J Clin Diagn Res 9: OC09-OC12, 2015.

11. Kraja B, Sina M, Mone I, Pupuleku F, Babameto A, Prifti S and Burazeri G: Predictive value of the model of end-stage liver disease in cirrhotic patients with and without spontaneous bacterial peritonitis. Gastroenterol Res Pract 2012: 539059, 2012.

12. Gonçalves PL, Zago-Gomes Mda P, Marques CC, Mendonça AT, Gonçalves CS and Pereira FE: Etiology of liver cirrhosis in Brazil: Chronic alcoholism and hepatitis viruses in liver cirrhosis diagnosed in the state of Espfrito Santo. Clinics (Sao Paulo) 68: 291-295, 2013.

13. Vento S, Dzudzor B, Cainelli F and Tachi K: Liver cirrhosis in sub-Saharan Africa: Neglected, yet important. Lancet Glob Health 6: e1060-e1061, 2018.

14. Metwally K, Fouad T, Assem M, Abdelsameea E and Yousery M: Predictors of spontaneous bacterial peritonitis in patients with cirrhotic ascites. J Clin Transl Hepatol 6: 372-376, 2018.

15. Abdel Rahman EM, Attia FA, Alsebaey A, Elkady MAK, Sayed MM, Awad AR and El-Seidi EA: Ascitic calprotectin as a useful marker in the diagnosis of spontaneous bacterial peritonitis in adults. Egypt Liver J 10: 1-6, 2020.

16. Elsadek HM, Elhawari SA and Mokhtar A: A novel serum index for accurate diagnosis of spontaneous bacterial peritonitis in cirrhotic patients without other infections. Egypt Liver J 10: 1-8, 2020.

17. Cai YJ, Dong JJ, Dong JZ, Yang NB, Song M, Wang YQ, Chen YP, Lin Z and Shi KQ: Neutrophil-lymphocyte ratio predicts hospital-acquired bacterial infections in decompensated cirrhosis. Clin Chim Acta 469: 201-207, 2017.

18. Piotrowski D, Saczewska-Piotrowska A, Jaroszewicz J and Boron-Kaczmarska A: Lymphocyte-to-monocyte ratio as the best simple predictor of bacterial infection in patients with liver cirrhosis. Int J Environ Res Public Health 17: 1727, 2020.

19. Abdel-Razik A, Mousa N, Abdel-Aziz M, Elsherbiny W, Zakaria S, Shabana W, Abed S, Elhelaly R, Elzehery R, Eldars W and El-Bendary M: Mansoura simple scoring system for prediction of spontaneous bacterial peritonitis: Lesson learnt. Eur J Gastroenterol Hepatol 31: 1017-1024, 2019.

20. Mousa N, Besheer T, Abdel-Razik A, Hamed M, Deiab AG, Sheta T and Eldars W: Can combined blood neutrophil to lymphocyte ratio and C-reactive protein be used for diagnosis of spontaneous bacterial peritonitis? Br J Biomed Sci 75: 71-75, 2018. 